\title{
Excitability of muscle fibre membranes in dystrophic mice
}

\author{
A. J. MCCOMAS AND S. J. MOSSAWY \\ From the Department of Physiology, University of Newcastle upon Tyne, and the \\ Department of Neurophysiology, Newcastle upon Tyne General Hospital
}

Electromyographic examination of patients with myotonia usually reveals fibres which intermittently fire high frequency trains of action potentials ('dive bomber discharges'). These potentials do not depend on motor neurone activity since they occur independently of willed movement and persist after impulse conduction in motor axons has been blocked (Buchthal and Clemmesen, 1941). The fact that d-tubocurarine is also ineffective in abolishing the action potentials (Floyd, Kent, and Page, 1955) indicates that they are not caused by acetylcholine acting at the end-plate or elsewhere along the fibre surface but must result from some intrinsic abnormality of the muscle fibre membrane.

It has recently been shown that muscles of dystrophic Bar Harbor mice also exhibit 'spontaneous' electrical activity (McIntyre, Bennett, and Brodkey, 1959; Lenman, 1963) and furthermore, that this has all the electrophysiological features described above for the human condition (McComas and Mossawy, 1965). These similarities indicated that the mice might form a suitable preparation in which to test the excitability of abnormal muscle fibre membranes directly, using the method of intracellular stimulation and recording; a similar investigation has been made in the myotonic goat by Bryant (1962). It appears that the critical depolarization of the membrane required for excitation is reduced in dystrophic mouse fibres; since, in addition, the membrane time-constant is increased it is possible that the change in excitability is associated with a fall in membrane conductance.

In the present study all the muscles have been examined in vivo and it has therefore been possible to compare some of the results obtained for normal fibres with those of earlier investigations in vitro (Boyd and Martin, 1956, 1959).

\section{METHODS}

PREPARATION Studies in vivo were made on seven normal and five dystrophic mice of the Bar Harbor 129 strain. The animals were anaesthetized with sodium pento- barbitone (Nembutal, Abbott Laboratories Ltd.) given intraperitoneally in an initial dose of $100 \mathrm{mg} . / \mathrm{kg}$. followed by smaller maintenance doses. An incision, $1-1.5 \mathrm{~cm}$. long, was made through the skin on the ventral aspect of the thigh, any loose subcutaneous fatty tissue was removed, and the underlying muscles (vastus medialis and gracilis) were exposed. The superficial muscle fibres were covered with a mammalian bathing fluid (Liley, 1956) kept at $28-33^{\circ} \mathrm{C}$; the animal was warmed by an electric blanket. After the electrophysiological investigation had been completed, the muscles were removed for histological examination and stained with haematoxylin and eosin.

STIMULATING AND RECORDING CIRCUIT (Fig. 1) $A_{\varrho}^{\stackrel{\overbrace{}}{\odot}}$ Wheatsone bridge was employed to allow the same microelectrode to be used for simultaneous stimulation and recording (cf. Araki and Otani, 1955; Beránek, 1964). Current was passed through the micro-electrode from the stimulator $\left(\mathbf{S}_{1}\right)$ and its magnitude was determined byco recording the voltage $\left(\mathrm{V}_{1}\right)$ dropped across a $1 \mathrm{M} \Omega$ series? resistance; the resulting change in fibre membrane potential $\left(\mathrm{V}_{2}\right)$ was also measured. Both $\mathrm{V}_{1}$ and $\mathrm{V}_{2}$ were fed through cathode followers to the d.c. amplifiers of a Tektronix type 502 oscilloscope. The d.c. component of the stimulus artefact was balanced out by adjusting the $25 \mathrm{k} \Omega$ potentiometer. In some experiments a second stimulator $\left(\mathbf{S}_{2}\right)$ was used to deliver a pulse which allowed the microelectrode resistance to be checked (for theory see Lettvin, Howland, and Gesteland, 1958).

The micro-electrodes were filled with $2 \mathrm{M}$ potassium citrate solution; in the bathing fluid they had d.c. resistances of $2-5 \mathrm{M} \Omega$ and tip potentials of less than $5 \mathrm{mV}$. The input time constant was not greater than $50 \mu \mathrm{sec}$. All the measurements were made by projecting $35 \mathrm{~mm}$. negatives of the oscilloscope traces on to squared paper.

VALIDITY OF METHOD The technique of stimulating and recording through a single microelectrode was chosen as it seemed to offer the best chance of investigating small muscle fibres. Such fibres are especially common in mouse dystrophy (Pearce and Walton, 1963), and, since they are known to have low resting potentials (Kleeman, Partridge, and Glaser, 1961), it was possible that their membranes might have been hyperexcitable as well. However, two pieces of evidence suggested that few of these small fibres were actually sampled in this study. 


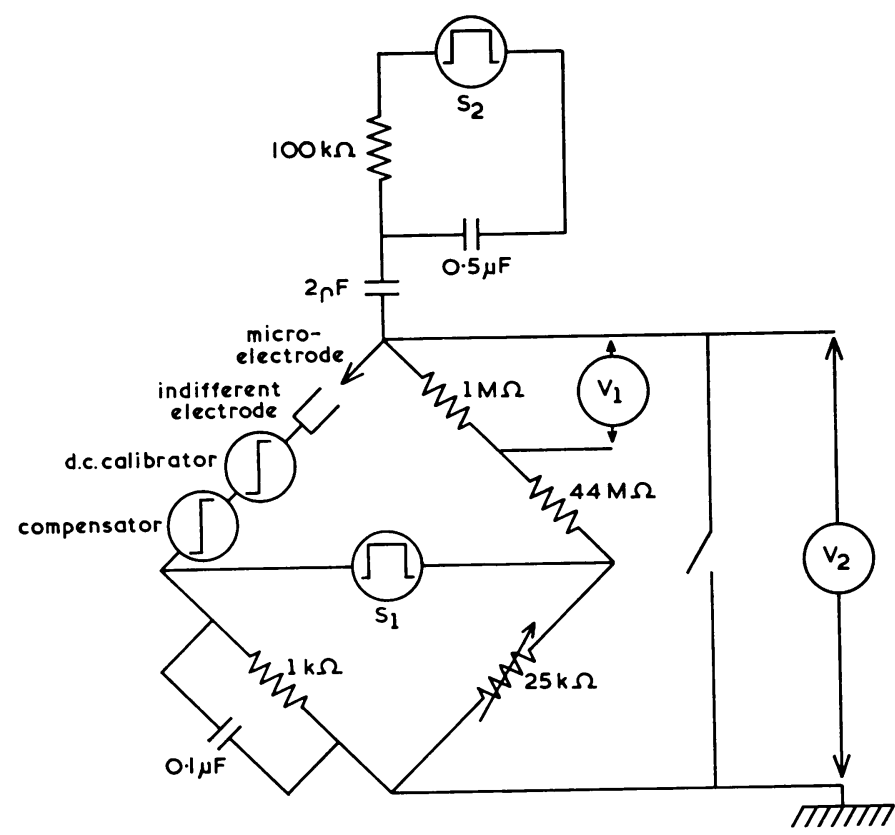

FIG. 1. Stimulating and recording arrangement utilizing Wheatstone bridge circuit (see text and also Beránek, 1964); m.e., micro-electrode; i.e., indifferent electrode.

First, the mean resting potential of dystrophic muscle fibres did not differ significantly from normal (see Table) whereas the inclusion of small fibres would have made it appreciably lower (Kleeman, et al., 1961; see above).

\section{TABLE}

MEAN ( \pm S.E.) VALUES OF RESTING POTENTIAL AND INPUT RESISTANCE OF NORMAL AND DYSTROPHIC FIBRES ${ }^{1}$

\begin{tabular}{lll} 
Muscle & $\begin{array}{l}\text { Resting Potential } \\
(\mathrm{mV})\end{array}$ & $\begin{array}{l}\text { Input Resistance } \\
\left(\times 10_{5}\right)\end{array}$ \\
\hline Normal & $80 \cdot 5 \pm 0 \cdot 7(50)^{2}$ & $1.94 \pm 0 \cdot 15(39)$ \\
Dystrophic & $79.1 \pm 1 \cdot 1(48)$ & $2 \cdot 15 \pm 0 \cdot 12(46)$
\end{tabular}

${ }^{1}$ Differences between normal and dystrophic means not significant $(P=>0 \cdot 2)$

${ }^{2}$ Figures in brackets denote the numbers of fibres investigated.

Secondly, the input resistance, measured as the change in membrane potential divided by the current flowing through the micro-electrode, did not show the significant rise which would have been expected had small fibres been sampled, i.e., since $\mathrm{R} \alpha \frac{1}{\mathrm{~d} \frac{3}{2}}$, where $\mathrm{R}$ is the input resistance and $\mathrm{d}$ the fibre diameter (cf. Katz and Thesleff, 1957).

This apparent lack of success in detecting small fibres was probably related to the sizes of the micro-electrodes employed in this study. It was found that micro-electrodes usually regarded as ideal for resting potential measurements and having d.c. resistances of 5-15M $\Omega$ showed appreciable rectification on passing current (cf. Beránek, 1964). This rectification had the effect of throwing the bridge out of balance and producing artefacts that might have been interpreted as changes in membrane potential. In our experience the rectification was made worse if pulses longer than $10 \mathrm{msec}$. were used or if the microelectrode was made cathodal instead of anodal, so that neither of these procedures could be employed. On the other hand, rectification was greatly reduced if microelectrodes with d.c. resistances of $2-5 \mathrm{M} \Omega$ were used. Although, for the reasons given above, these electrodes must have been too coarse to have impaled small muscle fibres, satisfactory penetrations could nevertheless be made in larger fibres and in these the observed resting potentials remained steady.

\section{RESULTS}

STRENGTHS OF CURRENT REQUIRED FOR EXCITATION When a muscle fibre had been successfully impaled, an anodal pulse of approximately $1 \times 10^{-8} \mathrm{~A}$ was applied through the micro-electrode and the resulting membrane depolarization was recorded. The strength of stimulus was then gradually increased and the smallest current which initiated an action potential was measured (Fig. 2a). The thresholds were determined in this way for 51 normal and 49 dystrophic fibres and the results are shown in Figure 3. It was found that although the range of values was similar in the two fibre populations, there were almost three times as many dystrophic fibres with thresholds of less than $4 \times 10^{-8} \mathrm{~A}$ and this caused the mean values for the two groups to differ significantly. An example of a dystrophic fibre with a low 


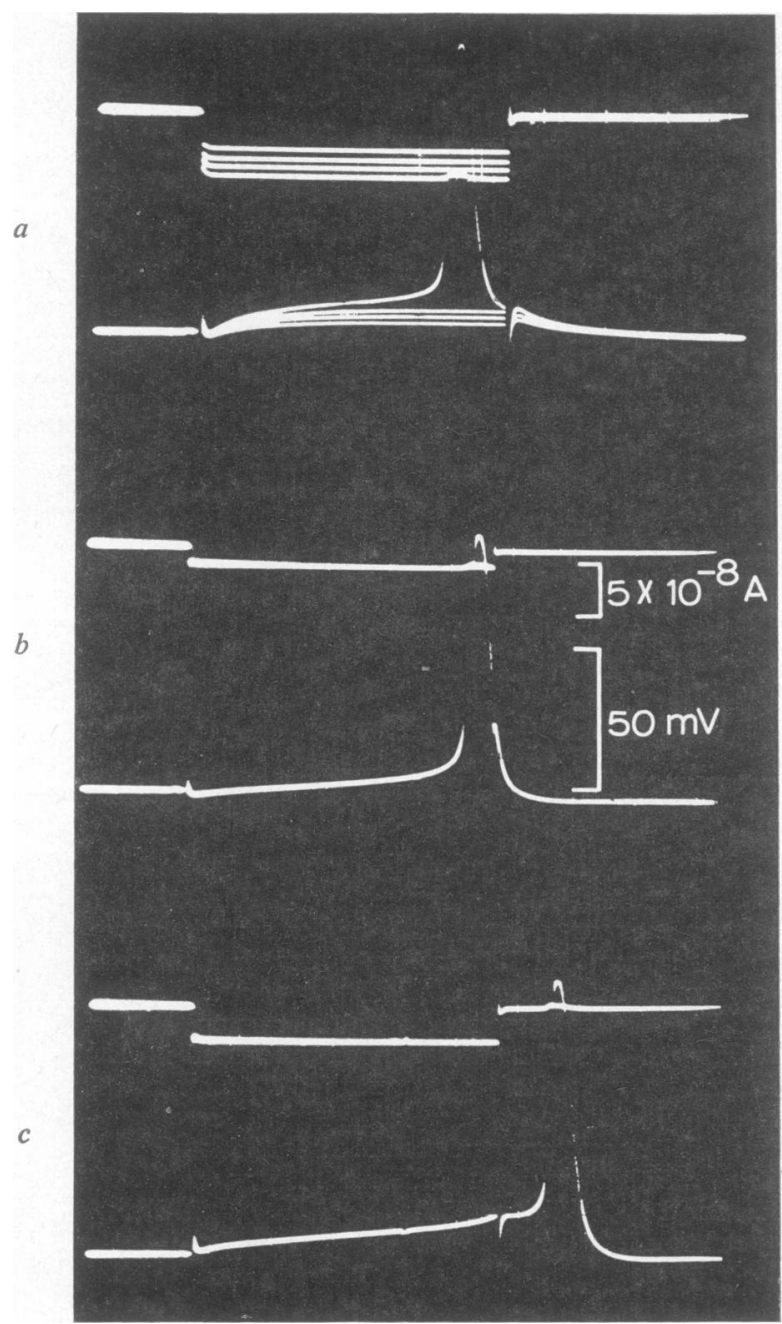

FIG. 2. Responses of three fibres to rectangular current pulses; (a) is a normal fibre while (b) and (c) are dystrophic (see text). For each fibre the top trace shows the current pulse (s) and the bottom trace, the evoked change in membrane potential. The separation between the top and bottom traces before the onset of current pulse is only an approximate indication of resting potential. The duration of the current pulses represents $10 \mathrm{msec}$.

threshold is shown in Fig. $2 \mathrm{~b}$; in this instance the excitatory current was $1.7 \times 10^{-8} \mathrm{~A}$.

The only other study in which threshold currents were measured for mammalian fibres in vivo appears to be that of Beránek (1964) who employed an ingenious technique to record from human hand muscles. He has reported values for normal fibres of between $1 \times 10^{-7}$ and $1 \times 10^{-8} \mathrm{~A}$, and the corre-

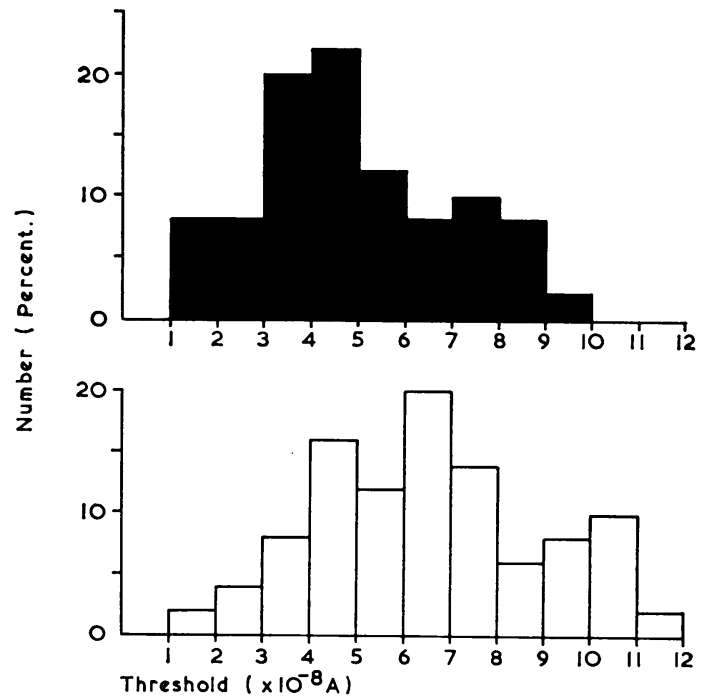

FIG. 3. Thresholds of 51 normal and 49 dystrophic fibres (open and filled columns respectively), measured as the smallest columns capable of initiating action potentials. Normal mean, $6.4 \pm 0 \cdot 3 \times 10^{-8} \mathrm{~A}$ (S.E.);dystrophic mean $4.9 \pm 0.3 \times 10^{-8} \mathrm{~A} ;$ means differed significantl $(P=<0.01)$.

sponding range from the present study was in agree ment $\left(1.7 \times 10^{-8}\right.$ to $\left.1.2 \times 10^{-7} \mathrm{~A}\right)$.

In some fibres, particularly dystrophic ones, it wa observed that the action potential spike occurres after the termination of the current pulse. Thes responses were not usually due to 'break' excitation o since the depolarization leading up to the spike had clearly begun before the stimulus had finished (e.g., Fig. 2c). It is possible that even later responses would have been recorded if it had been possible to use weaker currents of longer duration (see Methods). In this context it is of interest that in the myotonic goat Bryant (1962) has reported utilization times, measured between the onset of the pulse and the start of the action potential, of up to one second.

CRITICAL MEMBRANE DEPOLARIZATION The critical membrane depolarization was taken as the amount by which the resting potential had to be reduced by the applied current in order to initiate an action potential. This parameter was measured for normal and dystrophic fibres (Fig. 4) and the mean value for the latter was found to be significantly lower. It appeared that some dystrophic fibres could fire action potentials which were superimposed on electrotonic potentials as small as $6 \mathrm{mV}$. An important observation was that a fibre with a low threshold could have a normal resting potential and in such a fibre the reduction in critical membrane depolariza- N 

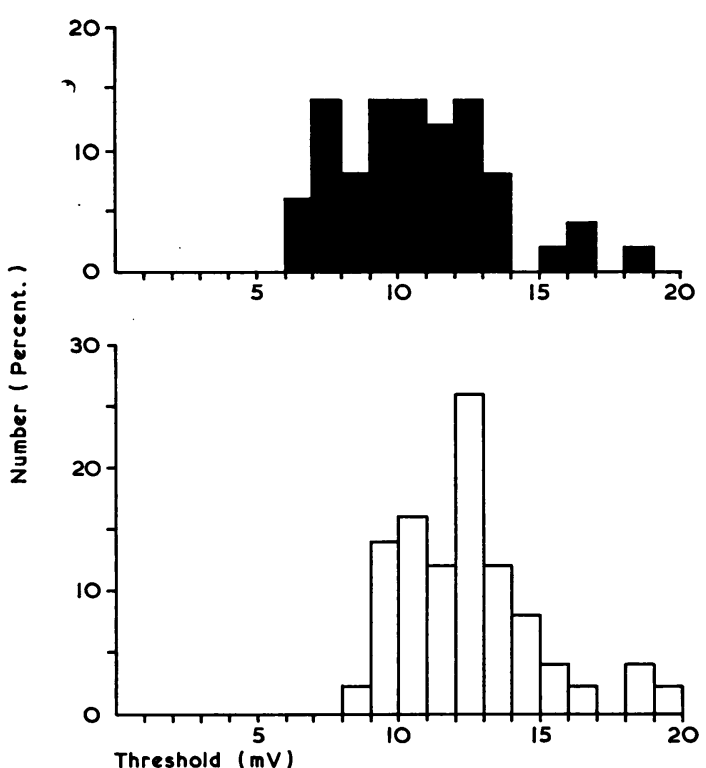

FIG. 4. Thresholds of 51 normal and 49 dystrophic fibres (open and filled columns respectively), measured in terms of critical membrane depolarization. Normal mean, $12.3 \pm 0.3 \mathrm{mV}$ (S.E.); dystrophic mean 10.5 $\pm 0.4 \mathrm{mV}$ (S.E.); means differed significantly $(P=<0.001)$.

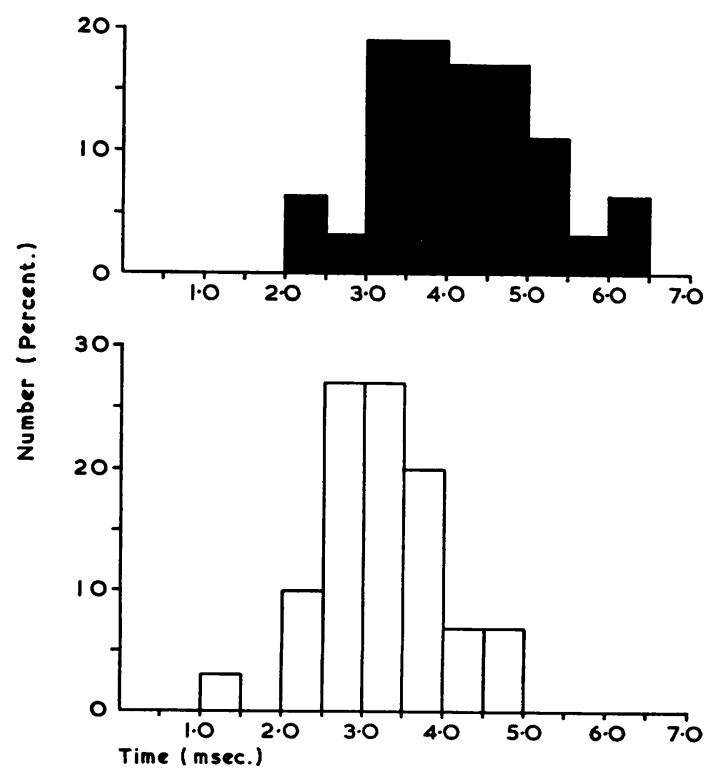

FIG. 5. Membrane time constants ( $\tau)$ of 30 normal and 36 dystrophic fibres (open and filled columns respectively). Normal mean 3.2 \pm 0.14 msec. (S.E.); dystrophic mean, $4 \cdot 1 \pm 0.17$ msec.; means differed significantly $(P=$ $<0.001)$. tion was therefore a consequence of a raised critical membrane potential, i.e., the p.d. across the membrane at which excitation occurs.

The only mammalian study available for comparison is that of Boyd and Martin (1956). They found the critical membrane depolarization for cat tenuissimus fibres to lie between 10 and $24 \mathrm{mV}$, compared with corresponding values of 8 to $20 \mathrm{mV}$ for normal fibres in the present investigation. However, at the time of recording the fibre resting potentials were rather lower in Boyd and Martin's study with means for individual muscles ranging from 56 to $66 \mathrm{mV}$, and therefore in such fibres the critical membrane potentials must also have been reduced.

MEMBRANE TIME CONSTANT The final part of the investigation concerned the membrane time constant which was measured as the time taken for the subthreshold electrotonic potential to reach $85 \%$ of its final value ( $c f$. Fatt and Katz, 1951). It was not possible to determine this parameter in all fibres, since in some an electrotonic potential never developed, but instead the membrane progressively depolarised until a spike was fired. This 'creep' of potential was noted by Katz and Thesleff (1957) in frog fibres and examples from the present study are shown in Figure $2(b, c)$. This type of behaviour was much commoner in dystrophic than in normal fibres and may therefore reflect an instability of diseased muscle fibre membranes.

A further distinction of dystrophic fibres was that their membrane time constants were usually longer than those of normal fibres (Fig. 5). Since the membrane time constant is equal to the product of the specific membrane resistance $\left(R_{m}\right)$ and the membrane capacitance $\left(C_{m}\right)$, either of these paramembers could have been increased in the dystrophic fibres. A rise in membrane resistance should also have caused a smaller increase in the input resistance (R), since $\mathrm{R} \alpha \sqrt{ } \mathbf{R}_{\mathrm{m}}$ ( $c f$. Katz and Thesleff, 1957); the $10 \%$ increase observed, though not significant statistically (see Table, above) was actually of the correct order.

It was noted that the input resistances of both normal and dystrophic fibres were rather less than half the values given by Boyd and Martin (1959). This discrepancy might have been partly attributable to the lower temperature of the superficial fibres in our study since Boyd and Martin showed that the membrane conductance, i.e., $\frac{1 \text {, }}{R_{m}}$ was temperature dependent. Also the calculation of input resistance could have been in error if current had been escaping through damaged membrane surrounding the electrode; however, this explanation seemed unlikely since the resting potentials were steady and of good 
amplitude. An alternative hypothesis deserving further study is that the membrane conductance, like the resting potential (McComas and Mossawy, 1965), is appreciably higher in vivo than in vitro.

\section{DISCUSSION}

Previous studies have shown that muscle fibres in dystrophic mice have electromyographic features characteristic of myotonia (McIntyre et al., 1959; Lenman, 1963; McComas and Mossawy 1965). The purpose of the present investigation has been to test the excitability of the dystrophic muscle fibre membrane directly using intracellular electrical stimulation. An important finding was that a much higher proportion of the dystrophic fibres could be made to fire action potentials with relatively small stimulating currents. One reason for this increased excitability was that the critical membrane depolarization required to trigger off the action potential was reduced in dystrophic fibres. However, an additional factor could have been a fall in membrane conductance since this would have resulted in a larger depolarization being produced by current flowing outwards through the muscle fibre membrane. The evidence for a reduced membrane conductance was indirect and rested on the finding of a longer membrane time constant in dystrophic fibres. A fall in conductance could have affected either the potassium or the chloride flux or both, since the former accounts for one third, and the latter for two thirds, of the transmembrane current when the membrane potential is near the resting level (Hutter and Noble, 1960 , frog sartorius muscle).

Of particular relevance to a consideration of membrane conductance in myotonia are the results obtained by Bryant (1962) for the muscles of myotonic goats. In these animals also there was evidence of a reduced critical membrane depolarization in association with a decreased membrane conductance. In addition, however, Bryant found that normal muscles became hyperexcitable when the chloride current had been abolished by bathing the fibres with solutions in which ferrocyanide or sulphate had been substituted for chloride. It is therefore possible that in the mouse and in the goat a reduction in chloride conductance is the basic defect in the muscle fibre membrane. A defect of this kind, occurring as a result of disease, would not be unique, since Hubbard (1963) has shown that there is also a fall in membrane conductance following denervation although in this case it is the potassium component which is affected.

It is uncertain to what extent the present findings are applicable to human myotonia since only two studies on patients have included measurements of membrane potential (Norris, 1962; Creutzfeldt, Abbott, Fowler, and Pearson, 1963). The patient of Creutzfeldt $e t$ al. suffered from adynamia episodica hereditaria associated with attacks of myotonia, while Norris investigated a similar case and also one of myotonia congenita; in both myotonic conditions a fall in resting potential was observed. A fall in resting potential is also common in mouse dystrophy (cf. McComas and Mossawy, 1965) but the present study and that of Bryant (1962) show that it is not a necessary condition for hyperexcitability. In conclusion, there is now enough evidence from animal studies to indicate the need for conductance measurements in human myotonia.

\section{SUMMARY}

An investigation of muscle fibre excitability in vivo has been made in dystrophic mice using the technique of intracellular stimulation and recording.

Dystrophic muscles differed from normal ones in that a larger proportion of fibres responded to relatively small stimulating currents; many of the dystrophic fibres also had reduced critical membrane depolarizations.

The fact that the membrane time constant was longer in dystrophic fibres suggested that theis membrane conductance might be decreased.

We are indebted to Mr. W. Jamieson for invaluable technical assistance and to Muscular Dystrophy Assos ciations of America, Inc., the Muscular Dystrophes Association of Canada, and the Muscular Dystroph $y^{+}$ Group of Great Britain for financial support.

\section{REFERENCES}

Araki, T., and Otani, T. (1955). Response of single motoneurons to direct stimulation in toad's spinal cord. J. Neurophysiol., 18, $472-485$.

Beránek, R. (1964). Intracellular stimulation myography in man. Electroenceph. clin. Neurophysiol., 16, 301-304.

Boyd, I. A., and Martin, A. R. (1956). The end-plate potential in mammalian muscle. J. Physiol. (Lond.), 132, 74-91.

- (1959). Membrane constants of mammalian muscle fibres. Ibid., 147, 450-457.

Bryant, S. H. (1962). Muscle membrane of normal and myotonic goats in normal and low external chloride. Fed. Proc., 21, 312.

Buchthal, F., and Clemmesen, S. (1941). Electromyographical observations in congenital myotonia. Acta psychiat. (Kbh.), 16, 389-403.

Creutzfeldt, O. D., Abbott, B. C., Fowler, W. M., and Pearson, C. M. (1963). Muscle membrane potentials in episodic adynamia. Electroenceph. clin. Neurophysiol., 15, 508-519.

Fatt, P., and Katz, B. (1951). An analysis of the end-plate potential recorded with an intracellular electrode. J. Physiol. (Lond.), I 115, 320-370.

Floyd, W. F., Kent, P., and Page, F. (1955). An electromyographic study of myotonia. Electroenceph. clin. Neurophysiol., 7, 621- N 630.

Hubbard, S. J. (1963). The electrical constants and the component conductances of frog skeletal muscle after denervation. $J$. O Physiol, (Lond.), 165, 443-456. 
Hutter, O. F., and Noble, D. (1960). The chloride conductance of frog skeletal muscle. Ibid., 151, 89-102.

Katz, B., and Thesleff, S. (1957). On the factors which determine the amplitude of the 'miniature end-plate potential'. Ibid., 137, 267-278.

Kleeman, F. J., Partridge, L. D., and Glaser, G. H. (1961). Resting potential and muscle fiber size in hereditary mouse muscle dystrophy. Amer. J. phys. Med., 40, 219-224.

Lenman, J. A. R. (1963). Micro-electrode studies in muscle disease. In Research in Muscular Dystrophy: Proc. Second Symposium of the Muscular Dystrophy Group, pp 230-239. Pitman Medical Publishing Co., London.

Lettvin, J. Y., Howland, B., and Gesteland, R. C. (1958). Footnotes on a headstage. I.R.E. Trans. Medical Electronics, ME-10, 26-28.

Liley, A. W. (1956). An investigation of spontaneous activity at the neuromuscular junction of the rat. J. Physiol. (Lond.), 132, 650-666.

McComas, A. J., and Mossawy, S. J. (1965). Electrophysiological investigation of normal and dystrophic muscles in mice. In Research in Muscular Dystrophy Proc. Third Symposium of the Muscular Dystrophy Group, pp. 317-341. Pitman Medical Publishing Co., London.

McIntyre, A. R., Bennett, A. L., and Brodkey, J. S. (1959). Muscle dystrophy in mice of the Bar Harbor strain. An electromyographic comparison with dystrophia myotonica in man. Arch. Neurol. Psychiat. (Chic.), 81, 678-693.

Norris, F. H. Jr. (1962). Unstable membrane potential in human myotonic muscle. Electroenceph. clin. Neurophysiol., 14, 197. 201.

Pearce, G. W., and Walton, J. N. (1963). A histological study of muscle from the Bar Harbor strain of dystrophic mice. J. Fath. Bact., 86, 25-33. 